\title{
Cancer Survival in Saudi Arabia 2005-2009: Analysis of the Population-based Saudi Cancer Registry
}

\author{
Mohamed Aseafan \\ King Faisal Specialist Hospital \& Research Centre \\ Edward Devol \\ King Faisal Specialist Hospital \& Research Centre \\ Mahmoud AlAhwal \\ King Abdulaziz University \\ Riad Souissi \\ Elm company \\ Reham Sindi \\ King Faisal Specialist Hospital \& Research Centre \\ Haya AlEid \\ Ministry of Health \\ Shouki Bazarbashi ( $\square$ bazarbashi@gmail.com ) \\ King Faisal Specialist Hospital \& Research Centre
}

Research Article

Keywords: Cancer, Survival, Cancer registry, Prognosis, Population-based, Saudi Arabia

Posted Date: April 28th, 2021

DOI: https://doi.org/10.21203/rs.3.rs-455335/v1

License: (c) (i) This work is licensed under a Creative Commons Attribution 4.0 International License. Read Full License 


\section{Abstract}

The Saudi Cancer Registry reported in 2007 the 5-year observed survival for the most common cancer sites for the years 1994-2004. In this report we looked at the cancer survival in the period 2005-2009 and evaluated the trend over the 15 years period from 1994-2009. Cases of the top 14 cancer sites reported by the population based Saudi Cancer Registry from 1 January 2005 to December 31, 2009 were submitted for survival analysis. The vital status of those patients was collected. Analysis of survival for the above period was compared with the prior reported 2 periods (1994-1999, 2000-2004). In addition, analysis was done according to age, sex, disease stage and the province. Data of 25,969 patients of the commonest cancer sites were submitted. Of those 14,146 (54\%) had complete demographic data available and vital status was reported. The observed 5-year survival for the 14,146 patients analyzed was $66 \%$. Thyroid cancer had the highest 5-year observed survival of 94\% (standard Error (SE) 0.0062), followed by Breast (72\%, SE 0.0085). In hematological malignancies, Hodgkin's Lymphoma had the highest 5-year survival of $86 \%$ (SE 0.0116). Survival rates has improved in most of the cancers sites for the studied periods except for lung, uterine and Hodgkin's lymphoma which plateaued. Our study confirms a steady improvement in the 5-year observed survival over time for the majority of cancers. Our survival data were comparable to western countries. This data should be used by policy makers to improve on cancer care in the kingdom.

\section{Introduction}

National cancer statistics represent important data on which decision makers depend for national cancer control strategies. The most frequently reported statistic is the cancer incidence, reported as the age standardized rate per 100,000. Less commonly, data on mortality and survival are reported. Changes in cancer incidence in a country might reflect the efficacy of the measures for primary and or secondary cancer prevention adopted in that country. On the other hand, survival statistics likely represent the efficacy of the therapeutic measures in addition to the preventive measures for addressing cancer in the population. Contrary to other chronic illnesses, survival in cancer patients represents one of the most significant outcome measures to be followed, despite the fact of its complexity being related the stage at diagnosis, the treatment offered, and other factors related to the health care system in the country.

The Kingdom of Saudi Arabia has an established national cancer registry since 1994 which reports mainly cancer incidence of the different cancer types and in the different regions of the Kingdom. Several attempts have been made to collect mortality data but were not successful. Despite an initial increase in cancer incidence, the Saudi cancer age standardized rate has plateaued and remains one of the lowest in the region. In 2007 the Saudi cancer registry reported the 5-year observed survival of the most common cancers for the years 1994-2004. The data represented the first national survival data reported across the region.

The health care system in Saudi Arabia is rapidly evolving with new medical cities and comprehensive cancer centers being established in most of the regions of the country over the past 10 years. In this report we have looked at the changing trend in survival for the most common cancers in Saudi Arabia between 1994-2009. Survival was calculated at 5-year intervals to establish the presence of change in recent years. In addition, we have looked at recent survival in different regions of the country to correlate with the availability of a comprehensive cancer care in each region.

\section{Methods}

Saudi citizens diagnosed with cancer are registered by the Saudi Cancer Registry (SCR). Cancer registration is an active process. Through the Cancer Registry offices located in the various provinces within the country, trained registrars are dispatched to every hospital, clinic or laboratory and register every newly diagnosed cancer patient. Large cancer centers with hospital-based registries transfer their data electronically to the main office of the Saudi Cancer Registry. The Saudi cancer registry collects demographic data including full name, national identification number, date of birth, region where diagnosis was made and topography of the cancer. First line management and vital status at follow up are collected only if time permits and accordingly are not complete. Cancers are defined according to the International Classification of Disease-Oncology. The SCR uses the CanReg-4 program provided by the International Agency for Research on Cancer (IARC, Lyon, France). Cancer incidence data are reported annually, and reports are published at the Saudi Health Council website. In addition, SCR data are reported in the Cancer in the Five Continents series with the latest being volume X [1]. In order to know the vital status of each patient diagnosed, a communication was done with Elm Company, a digital transformation company that delivers an integrated business solution for both public and private sectors in many different fields, including various data services for individuals and vehicles thru its partnership with the National Information Center.

Elm provided data related to cancer patients, including the date of death of those deceased. An abstract of all registered (01 January 2005 through 31 December 2009) cases from a list of the most common cancers (top 14 cancer sites) was requested from the SCR database. The abstract included each case's name, national identification number, date of birth and type of cancer. The vital status of those patients diagnosed was collected on 28 August 2019 and this date was considered the censoring date for those who were alive. In order for Elm company to report the vital status on the SCR abstract given to them, the patient's name (full name in Arabic which includes given name, father's name, grandfather's name, and family name), national identification number and date of birth had to match. Those with un-matching data were not reported to us.

The study was approved by the institutional review board at King Abdulaziz University Hospital. Since these were national data, we were exempted from obtaining informed consent from patients. Patient data were treated with strict confidentiality. Data were analyzed anonymously.

Survival was calculated from date of diagnosis to date of death or date of data capture (censoring) by the National Information Center. The Kaplan-Meier plot was used to calculate the survival according to age at diagnosis ( $\leq 40$ years and $>40$ years), sex, the province where the cancer diagnosis was made and disease stage. JMP statistical program (JMP version 15.0, 100 SAS Campus Drive, Cary, NC 27513 USA) was used for the Kaplan-Meier plots. Since the data for the period 1994-2004 were already published, the above analysis was made only for the later period of 2005-2009.

\section{Results}


A total of 25,969 patients diagnosed with the studied cancer sites were registered by the SCR between 1 January 2005 and 31 December 2009 . The number of patients diagnosed per cancer site is illustrated in Table 1. Of those 14,146 (54\%) were reported back to us on their vital status. Reasons for not reporting the rest were: $106(0.4 \%)$ patients had missing data, 148(0.6\%) patients had secondary cancer, $206(0.8 \%)$ patients were duplicate, $11110(43 \%)$ patients were rejected by Elm due to un-matching patient data, $25(0.1 \%)$ patients were not reported due to unknown causes and 228 ( $0.9 \%)$ patients due an illogical date of diagnosis and date of death ordering. Breakdown of the number submitted and analyzed per age, sex and stage is also illustrated in Table 1. It is apparent that the analyzed cases reflect a similar demographic distribution to the submitted cohort. The exception was thyroid cancer where $45.8 \%$ of the submitted cohort were more than 40 years while it was $86.2 \%$ in the analyzed cohort. Similarly, males represented $21.3 \%$ of the submitted cohort vs $37.9 \%$ of the analyzed one. The analysis below is based on the 14,146 patient cases returned.

Table 1

Number and percentage of patients submitted versus analyzed according to age, sex, and cancer stac

\begin{tabular}{|c|c|c|c|c|c|c|c|c|c|c|c|c|c|c|}
\hline \multirow{2}{*}{$\begin{array}{l}\text { Cancer } \\
\text { site }\end{array}$} & \multicolumn{9}{|c|}{ Submitted patients } & \multicolumn{5}{|c|}{ Analyzed patients } \\
\hline & $\begin{array}{l}\text { Total } \\
\text { Submitted }\end{array}$ & $\begin{array}{l}\text { Age } \\
>40 \\
(\%)\end{array}$ & $\begin{array}{l}\text { Age } \leq \\
40 \\
(\%)\end{array}$ & $\begin{array}{l}\text { Male } \\
\text { (\%) }\end{array}$ & $\begin{array}{l}\text { Female } \\
(\%)\end{array}$ & $\begin{array}{l}\text { Localized } \\
\text { (\%) }\end{array}$ & $\begin{array}{l}\text { Regional } \\
(\%)\end{array}$ & $\begin{array}{l}\text { Metastatic } \\
(\%)\end{array}$ & $\begin{array}{l}\text { Unknown } \\
\text { (\%) }\end{array}$ & $\begin{array}{l}\text { Total } \\
\text { Analyzed }\end{array}$ & $\begin{array}{l}\text { Age } \\
>40 \\
(\%)\end{array}$ & $\begin{array}{l}\text { Age } \leq \\
40 \\
(\%)\end{array}$ & $\begin{array}{l}\text { Male } \\
\text { (\%) }\end{array}$ & $\mathbf{F}$ \\
\hline Stomach & 1092 & 87.7 & 12.3 & 62.5 & 37.5 & 20.3 & 36.1 & 31.1 & 12.5 & 509 & 83.3 & 16.7 & 65 & 3 \\
\hline $\begin{array}{l}\text { Colo- } \\
\text { rectal }\end{array}$ & 3638 & 85.4 & 14.6 & 55.6 & 44.4 & 21.9 & 41.1 & 29.4 & 7.6 & 1891 & 85.5 & 14.5 & 56.5 & 4 \\
\hline Liver & 1599 & 93.6 & 6.4 & 71.3 & 28.7 & 30 & 11.2 & 16.1 & 42.7 & 731 & 94.8 & 5.2 & 72.6 & 2 \\
\hline Lung & 1485 & 94.3 & 5.7 & 76.7 & 23.3 & 9.4 & 14.2 & 57.9 & 18.5 & 767 & 93.9 & 6.1 & 79.8 & 2 \\
\hline Skin & 1024 & 84.6 & 15.4 & 59.7 & 40.3 & 68.2 & 8.5 & 3.4 & 19.9 & 427 & 93.4 & 6.6 & 65.4 & 3 \\
\hline Breast & 4780 & 71.2 & 28.8 & 0 & 100 & 30.5 & 46.2 & 16.6 & 6.7 & 2762 & 70.3 & 29.7 & 0 & 1 \\
\hline Uterine & 734 & 92.5 & 7.5 & - & 100 & 50.4 & 25.3 & 15 & 9.3 & 412 & 97.2 & 2.8 & - & 1 \\
\hline Ovarian & 658 & 71.4 & 28.6 & - & 100 & 18.8 & 12.9 & 58.4 & 9.9 & 383 & 81.3 & 18.7 & - & 1 \\
\hline Prostate & 1001 & 98.9 & 1.1 & 100 & - & 44.5 & 8.4 & 32.6 & 14.5 & 463 & 98.5 & 1.5 & 100 & - \\
\hline Bladder & 1138 & 91.3 & 8.7 & 83 & 17 & 60 & 16.6 & 12.2 & 11.2 & 532 & 94.9 & 5.1 & 84.9 & 1 \\
\hline Thyroid & 2409 & 45.8 & 54.2 & 21.3 & 78.7 & 50.7 & 32.2 & 7.3 & 9.8 & 1508 & 86.2 & 13.8 & 37.9 & 6 \\
\hline $\mathrm{HL}^{1}$ & 1355 & 27.7 & 72.3 & 58.4 & 41.6 & 14.7 & 29.2 & 42.3 & 13.8 & 896 & 38.9 & 61.1 & 59.4 & 4 \\
\hline $\mathrm{NHL}^{2}$ & 2661 & 67.2 & 32.8 & 60.4 & 39.6 & 19.6 & 17.6 & 45.4 & 17.4 & 1523 & 76.5 & 23.5 & 65.4 & 3 \\
\hline Leukemia & 2395 & 42.9 & 57.1 & 58.1 & 41.9 & - & - & - & - & 1504 & 37.7 & 62.3 & 64.9 & 3 \\
\hline
\end{tabular}

1. HL: Hodgkin Lymphoma, 2. NHL: Non-Hodgkin Lymphoma.

The observed 5-year survival for the 14,146 patients analyzed was 66\% as shown in Fig. 1.

5-year observed survival for the different cancers diagnosed in the period 2005-2009 is provided in Table 2. Of note, the highest survival in solid tumors was observed in thyroid cancer with a 5-year observed survival of $94 \%$ (standard error (SE) 0.0062 ), followed by breast (72\%, SE 0.0085 ), followed by uterine cancer $(68 \%$, SE 0.0230$)$, followed by bladder cancer $(59 \%$, SE 0.0213$)$ followed by ovarian cancer $(54 \%$, SE 0.0255$)$. In hematological malignancies, Hodgkin's Lymphoma had the highest 5-year survival (86\%, SE 0.0116), followed by leukemia (acute and chronic, 67\%, SE 0.0121) followed by Non-Hodgkin's lymphoma (64\%, SE 0.0123). 
Table 2

5-year observed survival for different cancers diagnosed in the period 2005-2009.

\begin{tabular}{|ll|}
\hline Cancer site & 2005-2009 (SE $\left.{ }^{1}\right)$ \\
\hline Stomach & $24 \%(0.0189)$ \\
\hline Colo-rectal & $52 \%(0.0115)$ \\
\hline Liver & $19 \%(0.0146)$ \\
\hline Lung & $11 \%(0.0119)$ \\
\hline Breast & $72 \%(0.0085)$ \\
\hline Uterine & $68 \%(0.0230)$ \\
\hline Ovarian & $54 \%(0.0255)$ \\
\hline Prostate & $49 \%(0.0233)$ \\
\hline Bladder & $59 \%(0.0213)$ \\
\hline Thyroid & $94 \%(0.0062)$ \\
\hline HL & \\
\hline NHL & 3
\end{tabular}

The 5 -year observed survival for different cancer sites in relation to age ( $\leq 40$ years versus $>40$ years) is illustrated in Table 3 . Of note, patients $\leq 40$ years of age did better in almost all cancer sites except for breast and prostate cancer and both results were not statistically significant.

Table 3

5-year observed survival for different cancer site for the year 2005-2009 according to

\begin{tabular}{|llll|}
\hline Cancer site & $>40\left(\mathrm{SE}^{1}\right)$ & $\leq 40(\mathrm{SE})$ & P value \\
\hline Stomach & $23 \%(0.0206)$ & $26 \%(0.0467)$ & 0.3110 \\
\hline Colo-rectal & $52 \%(0.0126)$ & $54 \%(0.0282)$ & 0.0145 \\
\hline Liver & $16 \%(0.0143)$ & $49 \%(0.0645)$ & $<.0001$ \\
\hline Lung & $11 \%(0.0119)$ & $20 \%(0.0566)$ & 0.0269 \\
\hline Skin & $73 \%(0.024)$ & $92 \%(0.0290)$ & $<.0001$ \\
\hline Breast & $73 \%(0.0101)$ & $72 \%(0.0157)$ & 0.8188 \\
\hline Uterine & $66 \%(0.0245)$ & $90 \%(0.0479)$ & 0.0004 \\
\hline Ovarian & $43 \%(0.0314)$ & $75 \%(0.0372)$ & $<.0001$ \\
\hline Prostate & $49 \%(0.0234)$ & $28 \%(0.1707)$ & 0.6278 \\
\hline Bladder & $57 \%(0.0229)$ & $77 \%(0.0530)$ & $<.0001$ \\
\hline Thyroid & $87 \%(0.0134)$ & $99 \%(0.0036)$ & $<.0001$ \\
\hline HL ${ }^{2}$ & $66 \%(0.0395)$ & $90 \%(0.0111)$ & $<.0001$ \\
\hline NHL & $54 \%(0.0168)$ & $78 \%(0.0165)$ & $<.0001$ \\
\hline Leukemia & $51 \%(0.0265)$ & $71 \%(0.0134)$ & $<.0001$ \\
\hline 1. SE: standard error $, 2 . \mathrm{HL}:$ Hodgkin Lymphoma, 3. NHL: Non-Hodgkin Lymphoma. & \\
\hline
\end{tabular}

Table 4 illustrate the 5-year observed survival for the different cancer sites according to sex. Findings indicate that males had worse survival in the following primary cancer sites (stomach, liver, lung, skin, thyroid, Non-Hodgkin lymphoma and leukaemia). However, colo-rectal, bladder cancers and Hodgkin's Lymphoma did not have a significant difference between males and females. 
Table 4

5-year observed survival for different cancer site for the year 2005-2009 according to

\begin{tabular}{|llll|}
\hline Cancer site & Male (SE') & Female (SE) & P value \\
\hline Stomach & $16 \%(0.0209)$ & $36 \%(0.0336)$ & $<.0001$ \\
\hline Colo-rectal & $51 \%(0.0155)$ & $54 \%(0.0171)$ & 0.2344 \\
\hline Liver & $16 \%(0.0164)$ & $26 \%(0.0295)$ & $<.0001$ \\
\hline Lung & $07 \%(0.0106)$ & $26 \%(0.0340)$ & $<.0001$ \\
\hline Skin & $72 \%(0.0285)$ & $83 \%(0.0280)$ & 0.0036 \\
\hline Bladder & $60 \%(0.0231)$ & $57 \%(0.0544)$ & 0.7257 \\
\hline Thyroid & $88 \%(0.0175)$ & $95 \%(0.0061)$ & $<.0001$ \\
\hline HL ${ }^{2}$ & $86 \%(0.0148)$ & $85 \%(0.0187)$ & 0.9801 \\
\hline NHL ${ }^{3}$ & $62 \%(0.0158)$ & $67 \%(0.0195)$ & 0.0071 \\
\hline Leukemia & $64 \%(0.0162)$ & $71 \%(0.0181)$ & $<.0001$ \\
\hline 1. SE: standard error, 2. HL: Hodgkin Lymphoma, 3. NHL: Non-Hodgkin Lymphoma. \\
\hline
\end{tabular}

Survival according to stage of disease is shown in Table 5. As expected, the 5-year observed survival was higher for localized disease in all cancers followed by regional and metastatic disease.

Table 5

5-year observed survival for different cancer site for the year 2005-2009 according to disease stage.

\begin{tabular}{|llllll|}
\hline Cancer site & Localized (SE & Regional (SE) & Metastatic (SE) & Unknown (SE) & $P$ value \\
\hline Stomach & $39 \%(0.052)$ & $26 \%(0.031)$ & $12 \%(0.025)$ & $24 \%(0.060)$ & $<.0001$ \\
\hline Colo-rectal & $73 \%(0.022)$ & $65 \%(0.017)$ & $21 \%(0.017)$ & $43 \%(0.048)$ & $<.0001$ \\
\hline Liver & $29 \%(0.027)$ & $13 \%(0.035)$ & $09 \%(0.026)$ & $14 \%(0.023)$ & $<.0001$ \\
\hline Lung & $36 \%(0.062)$ & $17 \%(0.033)$ & $06 \%(0.001)$ & $11 \%(0.031)$ & $<.0001$ \\
\hline Skin & $81 \%(0.022)$ & $61 \%(0.082)$ & $30 \%(0.118)$ & $73 \%(0.053)$ & $<.0001$ \\
\hline Breast & $88 \%(0.011)$ & $76 \%(0.012)$ & $35 \%(0.022)$ & $65 \%(0.039)$ & $<.0001$ \\
\hline Uterine & $81 \%(0.026)$ & $63 \%(0.046)$ & $28 \%(0.056)$ & $71 \%(0.084)$ & $<.0001$ \\
\hline Ovarian & $90 \%(0.035)$ & $67 \%(0.061)$ & $38 \%(0.032)$ & $62 \%(0.097)$ & $<.0001$ \\
\hline Prostate & $70 \%(0.031)$ & $43 \%(0.072)$ & $23 \%(0.035)$ & $42 \%(0.065)$ & $<.0001$ \\
\hline Bladder & $71 \%(0.025)$ & $41 \%(0.051)$ & $22 \%(0.055)$ & $59 \%(0.071)$ & $<.0001$ \\
\hline Thyroid & $98 \%(0.005)$ & $94 \%(0.009)$ & $58 \%(0.052)$ & $91 \%(0.025)$ & $<.0001$ \\
\hline HL ${ }^{2}$ & $94 \%(0.021)$ & $90 \%(0.018)$ & $82 \%(0.019)$ & $78 \%(0.043)$ & 0.0007 \\
\hline NHL ${ }^{3}$ & $78 \%(0.024)$ & $75 \%(0.026)$ & $57 \%(0.018)$ & $50 \%(0.036)$ & $<.0001$ \\
\hline 1. SE: standard error, $2 . \mathrm{HL}:$ Hodgkin Lymphoma, $3 . \mathrm{NHL}: \mathrm{Non}-\mathrm{Hodgkin} \mathrm{Lymphoma.}$ & \\
\hline
\end{tabular}

Table 6 demonstrates the 5-year observed survival for each cancer site in relation to Saudi Arabia's provinces. Significant Difference between provinces were noticed in breast cancer in the Northern Province as they had a lower 5-year observed survival by approximately $10 \%$ than other provinces in the Kingdom. Similarly, bladder cancer had lower 5 year observed survival in both the Western and Southern provinces compared to other provinces by $>25 \%$ relatively. 
Table 6

5-year observed survival for different cancer site for the year 2005-2009 according to province.

\begin{tabular}{|lllllll|}
\hline Cancer site & Eastern & Central & Western & Northern & Southern & P value \\
& $\left(\mathbf{S E}^{1}\right)$ & $(\mathrm{SE})$ & $(\mathrm{SE})$ & $(\mathrm{SE})$ & $(\mathrm{SE})$ & \\
\hline Stomach & $24 \%(0.044)$ & $27 \%(0.037)$ & $22 \%(0.030)$ & $14 \%(0.076)$ & $23 \%(0.053)$ & 0.7590 \\
\hline Colo-rectal & $58 \%(0.025)$ & $52 \%(0.019)$ & $50 \%(0.021)$ & $56 \%(0.058)$ & $47 \%(0.039)$ & 0.2117 \\
\hline Liver & $15 \%(0.033)$ & $20 \%(0.022)$ & $19 \%(0.029)$ & $08 \%(0.080)$ & $23 \%(0.050)$ & 0.4995 \\
\hline Lung & $11 \%(0.022)$ & $15 \%(0.031)$ & $08 \%(0.017)$ & $23 \%(0.031)$ & $04 \%(0.033)$ & 0.0581 \\
\hline Skin & $76 \%(0.044)$ & $80 \%(0.035)$ & $74 \%(0.037)$ & $73 \%(0.099)$ & $73 \%(0.065)$ & 0.1729 \\
\hline Breast & $72 \%(0.017)$ & $75 \%(0.014)$ & $71 \%(0.015)$ & $65 \%(0.042)$ & $71 \%(0.036)$ & 0.0305 \\
\hline Uterine & $73 \%(0.048)$ & $73 \%(0.041)$ & $66 \%(0.040)$ & $63 \%(0.100)$ & $50 \%(0.072)$ & 0.0740 \\
\hline Ovarian & $51 \%(0.059)$ & $59 \%(0.044)$ & $54 \%(0.045)$ & $45 \%(0.106)$ & $50 \%(0.076)$ & 0.6437 \\
\hline Prostate & $56 \%(0.043)$ & $45 \%(0.040)$ & $44 \%(0.043)$ & $44 \%(0.166)$ & $56 \%(0.080)$ & 0.1085 \\
\hline Bladder & $68 \%(0.040)$ & $63 \%(0.039)$ & $51 \%(0.037)$ & $72 \%(0.093)$ & $45 \%(0.080)$ & 0.0111 \\
\hline Thyroid & $92 \%(0.015)$ & $95 \%(0.009)$ & $94 \%(0.011)$ & $90 \%(0.035)$ & $94 \%(0.043)$ & 0.6371 \\
\hline HL ${ }^{2}$ & $87 \%(0.024)$ & $88 \%(0.018)$ & $83 \%(0.024)$ & $83 \%(0.052)$ & $84 \%(0.043)$ & 0.0588 \\
\hline NHL ${ }^{3}$ & $72 \%(0.027)$ & $63 \%(0.021)$ & $60 \%(0.022)$ & $68 \%(0.051)$ & $62 \%(0.042)$ & 0.0024 \\
\hline Leukemia & $62 \%(0.028)$ & $66 \%(0.022)$ & $71 \%(0.021)$ & $62 \%(0.051)$ & $70 \%(0.035)$ & 0.2185 \\
\hline 1. SE: standard error, 2. HL: Hodgkin Lymphoma, 3. NHL: Non-Hodgkin Lymphoma. & \\
\hline
\end{tabular}

The 5-year observed survival for different cancer sites was also compared to previously reported survival for the same cancers by the SCR. Table 7 shows the 5-year observed survival for the different time periods of 1994-1999, 2000-2004 and 2005-2009. Despite drop in survival for many cancers for the period 2000-2004, the 5-year observed survival was consistently better in all cancers in the period 2005-2009.

Table 7

5-year observed survival for different cancers over time.

\begin{tabular}{|llll|}
\hline Cancer site & $\mathbf{1 9 9 4 - 1 9 9 9}$ & $\mathbf{2 0 0 0 - 2 0 0 4}$ & $\mathbf{2 0 0 5 - 2 0 0 9}$ \\
\hline Stomach & $22.8 \%$ & $18.8 \%$ & $24 \%$ \\
\hline Colo-rectal & $44.7 \%$ & $44.3 \%$ & $52 \%$ \\
\hline Liver & $14.5 \%$ & $08.6 \%$ & $19 \%$ \\
\hline Lung & $13.8 \%$ & $6.5 \%$ & $11 \%$ \\
\hline Breast & $66.4 \%$ & $63.1 \%$ & $72 \%$ \\
\hline Uterine & $66.7 \%$ & $76.3 \%$ & $68 \%$ \\
\hline Ovarian & $46.7 \%$ & $47 \%$ & $54 \%$ \\
\hline Prostate & $37 \%$ & $41 \%$ & $49 \%$ \\
\hline Bladder & $44.7 \%$ & $43.4 \%$ & $59 \%$ \\
\hline Thyroid & $91.2 \%$ & $89 \%$ & $94 \%$ \\
\hline HL ${ }^{1}$ & $86.8 \%$ & $83.5 \%$ & $86 \%$ \\
\hline NHL ${ }^{2}$ & $51.7 \%$ & $58.9 \%$ & $64 \%$ \\
\hline Leukemia & $59.4 \%$ & $64 \%$ & $67 \%$ \\
\hline 1. HL: Hodgkin Lymphoma, 2. NHL: Non-Hodgkin Lymphoma. \\
\hline
\end{tabular}

\section{Discussion}

This is the first study evaluating population-based cancer survival in the Kingdom of Saudi Arabia. The study reports the 5-year observed survival for Saudi patients diagnosed with different cancers in the period from 2005-2009. It also examined the difference in the survival according to age, sex, disease stage, province, and the temporal trend over a 15-year period. 
The 5-year observed survival for all cancers studied combined in the period from 2005-2009 was 66\%. In general, most registries, report 5-year age standardized relative survival. Unfortunately, the required data to calculate this was not available for Saudi Arabia; hence, we are reporting 5-year observed survival.

Thyroid cancer had the best survival rate among solid tumors, similar to most reported registries. Thyroid cancer represents the second most common cancer in females and the third in the population in Saudi Arabia in the years reported [2,3]. Breast cancer represents the commonest cancer in Saudi females and in population in general. Despite a 5-year observed survival of $72 \%$, this represents a slightly lower value than western countries [4]. Reasons behind a lower survival are likely related to a relatively high percentage of presentation in advanced stage (12.5\%) and low rate of screening [5]. Screening for breast cancer has developed in several phases yet has not materialized into a national screening program [6-9]. Several opportunistic screening campaigns took place in several cities of Saudi Arabia mostly by non-governmental organizations [9]. Uterine cancer is generally related to nulliparity[10], which is uncommon is the Saudi population. 5-year observed survival is similar to other western countries [4]. Urinary bladder cancer is seen mostly in males with $84.4 \%$ of diagnosed cases in our study of male sex. Despite $10.7 \%$ of the patients studied being in metastatic stage, which is around double what is seen in the USA [11], the 5 -year observed survival of $59 \%$ was similar to western reports [4]. Colorectal cancer represents the commonest cancer in Saudi males and the second in the whole population [3]. The 5-year observed survival was remarkably similar to western data despite the latter representing cancer-specific survival. SEER data reported 54.8 and $57.7 \%$ 5-year cancer specific survival for colorectal cancer between 1990-1994 for males and females, respectively. This figure improved with a hazard ratio for improvement of 0.70 (95\% confidence internal 0.68-0.72) for the years 2004-2009 in white Americans [12]. Evidently, a major factor affecting our survival figures in colorectal cancer is the late presentation in Saudi population with $30 \%$ of our patients presenting in metastatic stage. In fact, data on colorectal screening rates in a sample of the Saudi population showed $5.6 \%$ screening rate with less than $1 \%$ utilizing colonoscopy [13].

Prostate cancer incidence is surprisingly low in Saudi Arabia with age-standardized rate (ASR) of 6.3/100,000 in 2016 [2]. This in contrast to a much higher reported incidence in USA and UK with ASR of 109 and 170 per 100,000 respectively[14, 15]. The reason for the low incidence may relate to it being secondary to the lack of PSA screening [16]. This might also be the reason for a higher incidence of advanced stage at presentation with $32 \%$ being metastatic at presentation and the lower 5-year observed survival of $49 \%$.

Liver cancer typically develops in patients with liver cirrhosis. The prevalence of hepatitis B infection in Saudi patients diagnosed with hepatocellular carcinoma (HCC) was reported to be $67 \%$ (95\% Cl: 57.7-75.3), with a much lower incidence of 11.9 for Hepatitis C virus [17]. Screening plays an important role in the detection of early stage HCC, which might make it more amenable for curative surgery [18]. Despite the implementation of a national vaccination program for hepatitis virus in 1989 in Saudi Arabia, the effect is not yet evident. Additionally, unfortunately no systematic screening for HCC is present in patients with cirrhosis, and hence the low 5-year observed survival rate of $19 \%$.

The hematological malignancies in Saudi Arabia have encouraging survival rates compared to western data [4]. Reasons behind this could be a usual early diagnosis in hematological malignancies and the available tertiary care centers that accept such cases promptly.

The survival difference by age has public health implications that need attention. In our study, younger patients did better in terms of survival similar to other countries. The exception was breast and prostate cancer, and both were not statistically significant $[4,12,19,20]$. Only 5 patients were younger than 40 years of age with prostate cancer which is expected due to higher median age at diagnosis. Older patients tend to have lower survival that may be explained by other comorbidities competing for death and are less likely to get aggressive therapy [19].

In our study, sex has displayed a prognostic role with females having better survival across all reported cancer sites except in urinary bladder cancer where the difference was not statistically significant. It is important to note that urinary bladder cancer occurs predominantly in males in our region [2, 3]. The survival superiority for females in cancer has been previously described in many populations in the literature $[4,19,21]$. Many hypotheses were proposed, of which that sex hormone patterns in female could play a role in providing a superior survival in females compared to males [4].

Cancer stage at diagnosis serves as one of the most important prognostic factors in generally all cancer sites. Patients with localized disease have an advantage in survival compared with locally advanced and metastatic disease in view of the possible surgical intervention. The staging system used in our study represents the one used by the CanReg-4 registry program supplied by IARC. We interpret our survival data with caution in view of the high number of unknown cancer stage in some sites. The lower survival seen in some cancers like stomach, lung and liver represent the usually advanced stage in which they present. In general, cancers which are known to have higher sensitivity to systemic therapies in advanced stages had markedly improved 5-year observed survival such as thyroid, Hodgkin's and non-Hodgkin's lymphoma.

Survival trends observed in our study confirmed the steady improvement in the 5-year observed survival over time. Lung and uterine cancer survival rates did plateau over the 15-year period studied. Hodgkin's lymphoma had an excellent survival rate of $86 \%$ in the period $1994-1999$ and this was maintained in the years 2005-2009. These survival trends need to be interpreted with caution as many factors might have played a role like health care accessibility, care quality, staff expertise, treatment availability and statistical artifacts [19]. One important factor is the continued improvement in anticancer therapy. Additionally, the health care system has advanced with time. This might be behind the improvement in the 5-year observed survival over time.

Survival results from the Northern province underperformed other provinces in the Kingdom of Saudi Arabia. This could be explained by lack of oncology centers and patient education in that province. Acknowledging these defects helps to tackle these issues leading to improvement in survival.

Population-based survival may give an insight into the effectiveness of the health care system in managing cancer patients [19]. Achieving better cancer control is a global health challenge that is used as a tool to assess the health care system efficacy and helps as guide if improvement is required by comparing population survival rates with others. The CONCORD-3 study is one of the biggest global comparative studies with 322 separate registries in 71 countries covering approximately 1 billion people of the global population. It investigated patients diagnosed with cancer between $2000-2014$ and has shown 
that survival trends were in general on an upwards trend. However, it was clear that high-income countries enjoy better survival than low-middle income countries [22].

As the population in Saudi Arabia continues to grow, the incidence of cancer has increased from 1990 to 2016 [23]. The SCR is the first national registry in Saudi Arabia established in 1992 by a resolution of the Minister of Health. It is one of first registries founded in the region. However, clearly efforts are needed to improve the registration process to get a more comprehensive survival and mortality data in the future.

Comparative survival results between populations and countries help health care officials to identify issues with the current health care system and possibly formulate national cancer strategies to improve cancer control $[22,24]$. The need for a national cancer screening programs in Saudi Arabia should be carefully studied. This is because the incidence of cancer in general in Saudi Arabia is much below western levels and the benefit of mass screening is not known.

Our study has several limitations. First, only $54 \%$ of cancer cases submitted were analyzed as the required data was not available for the others. On the other hand, this percentage likely represents one of the highest reported survival studies on a national level. An additional limitation was our inability to produce relative survival rates in view of the lack of the denominator data.

In summary, the relatively lower observed survival in some solid tumors may represent the advanced stage at presentation. Hematological malignancies have 5-year observed survival comparable to the developed countries. A positive trend in cancer survival over time was seen in most cancers. The Saudi cancer registry needs to develop a systematic method for capturing mortality and survival data with time. This study highlights the need for future studies assessing the role of screening programs for early diagnosis which could lead to improving the overall survival of cancer in the Kingdom of Saudi Arabia.

\section{Declarations}

\section{Authors' contributions:}

R.S., M.A.A., H.A.E., and S.B. drafted the study design. E.D. and R.S. did the statistical analysis of the data. M.A. and S.B. prepared the tables. M.A., M.A.A., and S.B. analyzed the data. M.A. and S.B. drafted the report. S.B. did the overall supervision of the study. All authors contributed to data interpretation and reviewed and approved the final version of the manuscript.

\section{Funding:}

No funds, grants, or other support was received.

\section{Acknowledgments:}

We gratefully acknowledge the cooperation of Saudi Cancer Registry in providing cancer records, data collection, sorting, verification, and database creation.

\section{Competing interests:}

The authors have no financial or proprietary interests in any material discussed in this article.

\section{Data availability:}

All data and documents needed will be provided upon request through email: bazarbashi@kfshrc.edu.sa

\section{Ethical approval:}

This study was performed in line with the principles of the Declaration of Helsinki. Approval was granted by the Ethics Committee at King Abdulaziz University Hospital (Date 21 April 2020/No. 215-20)

\section{Consent to participate:}

Since the study involve retrospective national registry data, we were exempted from obtaining informed consent from patients.

\section{References}

1. Cancer Incidence in Five Continents, ed. F.B. D. Forman, D.H. Brewster, C. Gombe Mbalawa, B. Kohler, M. Piñeros, E. Steliarova-Foucher, R. Swaminathan and J. Ferlay Vol. Volume X. 2014, Lyon, France: The International Agency for Reseach on Cancer. 1365.

2. National Health Information Center. Cancer Incidence Report, Saudi Arabia, 2009 [cited 202131 January 2021]; Available from: https://nhic.gov.sa/en/eServices/Pages/TumorRegistration.aspx.

3. Bazarbashi, S., H. Al Eid, and J. Minguet, Cancer Incidence in Saudi Arabia: 2012 Data from the Saudi Cancer Registry. Asian Pac J Cancer Prev, 2017. 18(9): p. 2437-2444.

4. Chirlaque, M.D., et al., Cancer survival in adult patients in Spain. Results from nine population-based cancer registries. Clin Transl Oncol, 2018. 20(2): $\mathrm{p}$. 201-211.

5. El Bcheraoui, C., et al., Breast cancer screening in Saudi Arabia: free but almost no takers. PLoS One, 2015. 10(3): p. e0119051.

6. Al Mulhim, F.A., et al., Breast cancer screening programme: experience from Eastern province, Saudi Arabia. East Mediterr Health J, 2015. 21(2): p. 111-9. 
7. Abulkhair, O.A., et al., The first national public breast cancer screening program in Saudi Arabia. Ann Saudi Med, 2010. 30(5): p. 350-7.

8. Akhtar, S.S., et al., First organized screening mammography programme in Saudi Arabia: preliminary analysis of pilot round. East Mediterr Health J, 2010. 16(10): p. 1025-31.

9. Gosadi, I.M., National screening programs in Saudi Arabia: Overview, outcomes, and effectiveness. J Infect Public Health, 2019. 12(5): p. 608-614.

10. Gleicher, N., Why are reproductive cancers more common in nulliparous women? Reprod Biomed Online, 2013. 26(5): p. 416-9.

11. Cancer Stat Facts: Bladder Cancer. 2021 [cited 202131 January 2021]; Available from: https://seer.cancer.gov/statfacts/html/urinb.html.

12. Zeng, C., et al., Disparities by Race, Age, and Sex in the Improvement of Survival for Major Cancers: Results From the National Cancer Institute Surveillance, Epidemiology, and End Results (SEER) Program in the United States, 1990 to 2010. JAMA Oncol, 2015. 1(1): p. 88-96.

13. Khoja, A., et al., Utilization of Colorectal Cancer Screening among Saudi Elderly Population: A Study from the Saudi National Survey for Elderly Health. Asian Pac J Cancer Prev, 2018. 19(12): p. 3401-3407.

14. Cancer Reaserch UK. Prostate Cancer Incidence Statistics 2021 [cited 202131 January 2021]; Available from: https://www.cancerresearchuk.org/healthprofessional/cancer-statistics/statistics-by-cancer-type/prostate-cancer/incidence\#heading-Zero.

15. Cancer Stat Facts: Prostate Cancer. 2020 [cited 202131 January 2021]; Available from: https://seer.cancer.gov/statfacts/html/prost.html.

16. Arafa, M.A. and D.M. Rabah, With increasing trends of prostate cancer in the Saudi Arabia and Arab World: Should we start screening programs? World J Clin Oncol, 2017. 8(6): p. 447-449.

17. Ayoola, E.A. and M.O. Gadour, Hepatocellular carcinoma in Saudi Arabia: role of hepatitis B and C infection. J Gastroenterol Hepatol, 2004. 19(6): p. 665-9.

18. Wong, L.L., et al., Improved survival with screening for hepatocellular carcinoma. Liver Transpl, 2000. 6(3): p. 320-5.

19. Zeng, H., et al., Changing cancer survival in China during 2003-15: a pooled analysis of 17 population-based cancer registries. Lancet Glob Health, 2018. 6(5): p. e555-e567.

20. Arnold, M., et al., Progress in cancer survival, mortality, and incidence in seven high-income countries 1995-2014 (ICBP SURVMARK-2): a population-based study. Lancet Oncol, 2019. 20(11): p. 1493-1505.

21. Bossard, N., et al., Survival of cancer patients in France: a population-based study from The Association of the French Cancer Registries (FRANCIM). Eur J Cancer, 2007. 43(1): p. 149-60.

22. Allemani, C., et al., Global surveillance of trends in cancer survival 2000-14 (CONCORD-3): analysis of individual records for 37513025 patients diagnosed with one of 18 cancers from 322 population-based registries in 71 countries. Lancet, 2018. 391(10125): p. 1023-1075.

23. Althubiti, M.A. and M.M. Nour Eldein, Trends in the incidence and mortality of cancer in Saudi Arabia. Saudi Med J, 2018. 39(12): p. 1259-1262.

24. Rossi, S., et al., The EUROCARE-5 study on cancer survival in Europe 1999-2007: Database, quality checks and statistical analysis methods. Eur J Cancer, 2015. 51(15): p. 2104-2119.

\section{Figures}

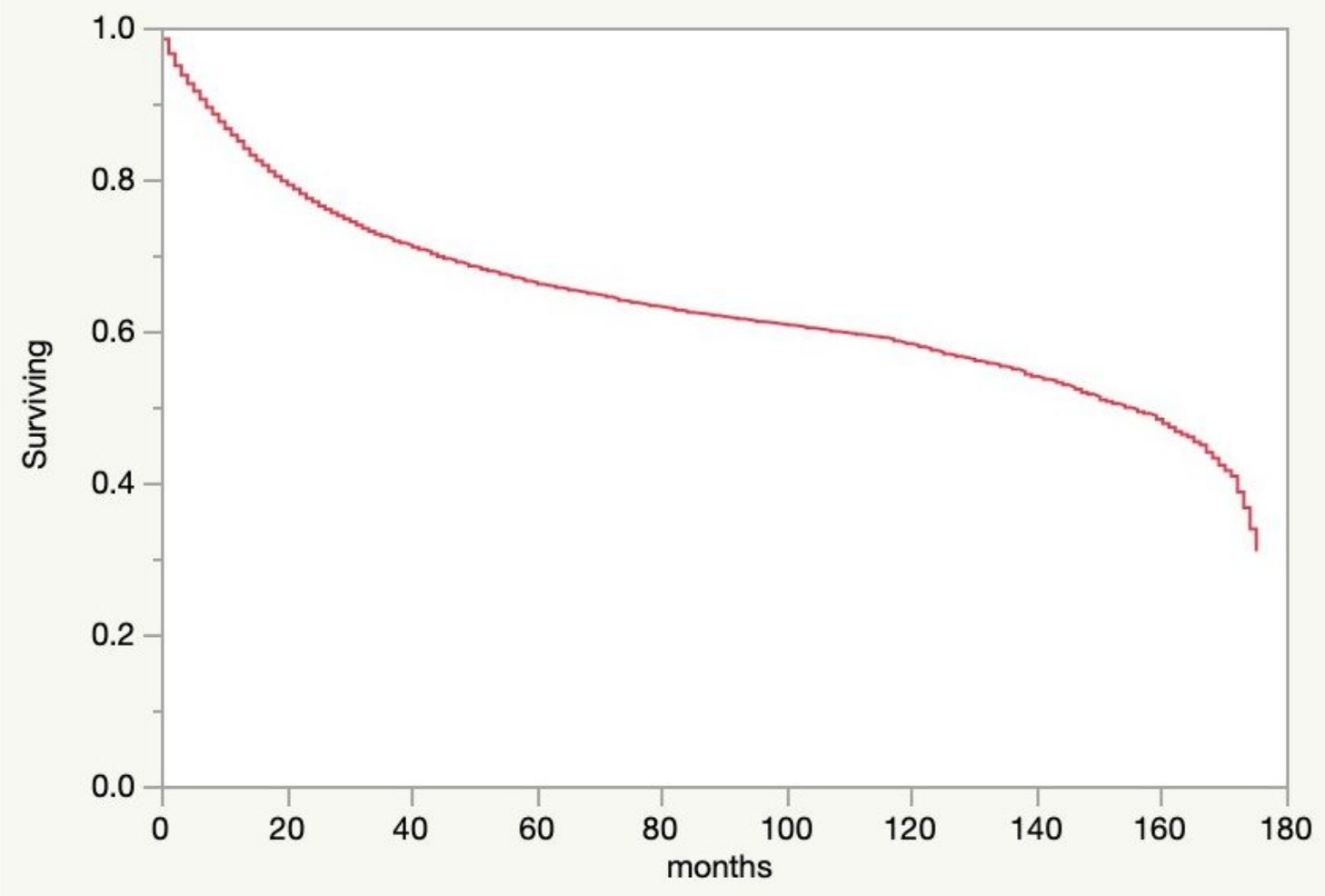


Figure 1

Kaplan-Meier curve of observed survival for all analyzed cancer cases combined in the period 2005-2009.

Page $10 / 10$ 